\title{
Outorgas de recursos hídricos na bacia hidrográfica do Rio Jaru em Rondônia: Amazônia meridional
}

A Lei no 9.433/1997 é um marco na gestão das águas no Brasil, apresentando como um de seus instrumentos a outorga de direito de uso dos recursos hídricos, que tem por finalidade assegurar o controle quantitativo e qualitativo dos usos da água e garantir o efetivo exercício do direito de acesso a todos. O objetivo desse estudo foi efetuar um levantamento das outorgas emitidas pela Secretaria de Estado do Desenvolvimento Ambiental (SEDAM), no período de 2010 a 2019 na bacia hidrográfica do Rio Jaru, no Estado de Rondônia, localizada na Amazônia Meridional Brasileira, bem como elaborar um diagnóstico dos diferentes usuários e das finalidades de uso das águas superficiais e subterrâneas. Essas informações foram organizadas em tabelas e representações gráficas e georreferenciadas para a elaboração dos mapas de espacialização das outorgas. Os resultados possibilitaram caracterizar os usuários de água na bacia sendo identificado que a grande maioria das outorgas foi de águas superficiais ( $84 \%$ e, deste montante, o principal uso é para a piscicultura (79\%); já em relação às outorgas emitidas para a sendo identificado que a grande maioria das outorgas foi de águas superficiais ( $84 \%)$ e, deste montante, o principal uso é para a piscicultura (79\%); já em relação às outorgas emitidas para a
utilização das águas subterrâneas, a bacia apresentou um total menor, cuja finalidade de uso dominante foi o doméstico (48\%), seguido pelo uso industrial (44\%). Também foi mapeado o desmatamento na área objeto de estudo, até agosto de 2019, através do Programa de Desmatamento (PRODES) Digital do Instituto Nacional de Pesquisas Espaciais (INPE) em função da expressiva ocupação por projetos do Instituto Nacional de Colonização e Reforma Agrária (INCRA). Em vista da elevada antropização da bacia e seus impactos negativos nas águas, faz-se necessário agilizar a instalação do Comitê da bacia hidrográfica do Rio Jaru - Baixo Machado/RO; deflagrar uma ampla conscientização da sociedade, quanto à utilização racional da água juntamente com uma campanha para regularização dos usuários de águas que ainda não possuem cadastro no órgão gestor dos recursos hídricos em Rondônia para que este colegiado, atualmente apenas legalmente instituído, tão logo seja implantado, possa priorizar ações de recuperação de áreas degradadas, a exemplo das matas ciliares e crescente escassez de água na bacia durante o período de estiagem, atuando na mediação de conflitos entre usuários de água.

Palavras-chave: Outorga; Usuários de água; Rio Jaru; Rondônia; Amazônia.

\section{Granting of water resources in the Jaru River hydrographic basin in Rondônia: Southern Amazonia}

\begin{abstract}
Law 9.433/1997 is a milestone in the management of water resources in Brazil. It includes as one of its instruments the permit for the use of water resources that aims to assure the quantitative and qualitative control of water use and guarantee the effective right of access to all citizens. The aim of this study was to survey the permits issued by the Secretariat of State for Environmental Development (SEDAM, in the Portuguese acronym) from 2010 to 2019 in the Jaru River basin, in the state of Rondônia, Southern Brazilian Amazon, as well as identify the for Environmental Development (SEDAM, in the Portuguese acronym) from 2010 to 2019 in the Jaru River basin, in the state of Rondonia, Southern Brazilian Amazon, as well as identify the different users and the purpose of use of superficial and groundwater. This information was organized in tables and graphic representations and georeferenced for the elaboration of spatial
maps of the permits. The results allowed us to identify the water users of the aforementioned basin. It also indicated that most of the permits refer to superficial water ( $84 \%$ ) and that $79 \%$ of this is used for fish farming. The permits issued for the use of groundwater of the basin present a smaller total, and domestic use is the main purpose of these waters (48\%), followed by industrial use (44\%). The study also mapped the deforestation in the area related to this study until August 2019 through the Deforestation Program (PRODES, Portuguese acronym) of the National Institute of Space Research (INPE, Portuguese acronym) due to the expressive number of projects of the National Institute of Colonization and Land Reform (INCRA, Portuguese acronym). Considering the great anthropization of the basin and its negative impacts on the waters, a number of actions are essential. For example, the establishment a committee for the Jaru River Basin - Baixo Machado/RO; the launch of an awareness campaign about the rational use of water and a campaign to regularize the record of water users in the water resource management body in Rondônia. This will allow this collegiate, which nowadays is only legally instituted, as soon as it is implanted, to prioritize recovery actions of degraded areas such as the riparian forests and increasing lack of water during the dry season, acting in the mediation of conflicts between the water users.
\end{abstract}

Keywords: Permit; Water users; Jaru River; Rondônia; Amazon.

Topic: Engenharia de Recursos Hídricos

Reviewed anonymously in the process of blind peer.

Ana Paula Alves Gonçalves (i)

Universidade Federal de Rondônia, Brasil

http://lattes.cnpq.br/2157955227549867

http://orcid.org/0000-0001-7141-0865

ana.goncalves@ifro.edu.br

\section{Catia Eliza Zuffo (iD}

Universidade Federal de Rondônia, Brasil

http://lattes.cnpq.br/8878662417344970

http://orcid.org/0000-0002-5637-463X

catiazuffo@unir.br

Grasiela Rocha Torres Goveia

Universidade Federal de Rondônia, Brasil http://lattes.cnpq.br/4464403749162787 http://orcid.org/0000-0001-7818-2834

grasiela.torres@gmail.com
Received: 02/02/2021

Approved: 27/02/2021

Osmair Oliveira dos Santos

Universidade Federal de Rondônia, Brasi

http://lattes.cnpq.br/7047645403114376

http://orcid.org/0000-0002-8489-3760

osmairsantos@gmail.com
Referencing this:

GONÇALVES, A. P. A.; ZUFFO, C. E.; GOVEIA, G. R.; SANTOS, O. O.. Outorgas de recursos hídricos na bacia hidrográfica do Rio Jaru em Rondônia: Amazônia meridional. Revista Ibero Americana de Ciências Ambientais, v.12, n.2, p.279-291, 2021. DOI: http://doi.org/10.6008/CBPC2179-6858.2021.002.0026 


\section{INTRODUÇÃO}

Nas últimas décadas, a água tornou-se objeto de conflito pelos múltiplos usuários, urbanos e rurais, diante do aumento da demanda e à escassez da oferta. A preocupação com os impactos das atividades humanas sobre o meio ambiente cresce a cada dia, necessitando de uma gestão eficiente sobre esse bem de domínio público.

A disponibilidade de água doce limpa é potencialmente uma das maiores preocupações que a sociedade mundial terá de enfrentar e adaptar-se nos próximos anos, uma vez que existe crescente pressão sobre esse recurso para os diversos usos, tais como: geração de energia elétrica, uso doméstico, uso industrial, mineração e irrigação, associados à redução da qualidade da água, devido ao lançamento de diversos efluentes, mostram um potencial de conflito pelo uso da água.

A Política Nacional de Recursos Hídricos, através da Lei Federal no 9.433/1997, tem como um dos seus princípios básicos que a gestão dos recursos hídricos deve ser descentralizada, com a participação do poder público, dos usuários e da sociedade (BRASIL, 1997). Surge dessa forma a figura dos Comitês de Bacias Hidrográficas, que possuem poder deliberativo, propositivos e consultivos, e têm como papel principal o debate das questões locais sobre recursos hídricos, buscando consenso sobre os múltiplos interesses e usos da água na bacia.

A lei 9.433/1997 também traz um importante instrumento que auxilia no processo de gestão dos recursos hídricos, estabelecido no artigo 5으, a outorga que possui por finalidade "assegurar o controle quantitativo e qualitativo dos usos da água e o efetivo exercício dos direitos de acesso à água" (BRASIL, 1997).

Desta forma, a outorga possui dupla finalidade, pois confere aos usuários que a vazão outorgada não será utilizada por terceiros, garantindo assim o quantitativo de água necessário para sua atividade e para a administração pública e uma melhor gestão desse recurso, devido ser de conhecimento dos usuários, as finalidades de uso, proporcionando uma melhor articulação com os demais instrumentos da Política Nacional de Recursos Hídricos (ANA, 2019).

No estado de Rondônia, a Lei complementar no 255, de 25 de janeiro de 2002, institui a Política Estadual de Recursos Hídricos e tem como base os fundamentos da Lei Federal no 9.433/97 (RONDÔNIA, 2002a). Em relação à outorga no estado de Rondônia, o Decreto Estadual no 10.114/2002, apresenta informações acerca da Outorga Preventiva e Outorga do Direito de Uso de Recursos Hídricos, especialmente em seu Artigo 34:

Dependerá da outorga de direito de uso, todos os usos e intervenções que alterem o curso natural dos corpos de água, ou as condições quantitativas ou qualitativas tais como:

I- Derivações ou captações de água superficial ou aquífero subterrâneo, para consumo final, inclusive para abastecimento público ou insumo de processo produtivo;

II - Lançamento, em corpo de água, de dejetos, águas servidas e demais resíduos líquidos, sólidos ou gasosos, tratados ou não, com o fim de sua diluição, transporte ou disposição final;

III - Aproveitamentos de potenciais hidrelétricos; $\mathrm{e}$

IV - Outros usos que alterem o regime, qualidade ou quantidade da água. (RONDÔNIA, 
2002b)

Quanto aos usos da água que independem de outorga, o Artigo 35 da mesma legislação (RONDÔNIA, 2002b), indica os seguintes:

I - a satisfação das necessidades de pequenos núcleos populacionais, distribuídos no meio rural;

II - As derivações, captações e lançamentos considerados insignificantes; e

III - As acumulações de volumes de água, consideradas insignificantes.

A Agência Nacional de Águas e de Saneamento Básico (ANA) é a responsável pela análise e emissão da outorga de direito do uso de recursos hídricos em corpos hídricos de domínio da União e a solicitação de outorga dos corpos hídricos de domínio dos Estados e do Distrito Federal deve ser feita às respectivas autoridades estaduais, no caso do Estado de Rondônia, o órgão responsável é a Secretaria de Estado do Desenvolvimento Ambiental (SEDAM).

Segundo Porto et al. (2008), "a exceção, prevista na própria legislação, são os usos considerados como insignificantes, isentos da obrigatoriedade de obtenção de outorgas, mas definidos localmente em cada bacia hidrográfica e pelos respectivos comitês, em função das disponibilidades hídricas e demandas locais".

O Conselho Estadual de Recursos Hídricos - CRH/RO, através da Resolução n 04, definiu os usos considerados insignificantes para o estado de Rondônia até que os $\mathrm{CBHs}$ tenham estabelecidos em suas bacias hidrográficas. Esses usos não são objeto de outorga pela SEDAM, mas, obrigatoriamente, de registro no Cadastro Nacional de Usuários de Recursos Hídricos - CNARH (RONDÔNIA, 2014a).

O objetivo desse estudo foi efetuar um levantamento das outorgas emitidas pela SEDAM, no período de 2010 a 2019, na bacia hidrográfica do Rio Jaru, no Estado de Rondônia, localizada na Amazônia Meridional Brasileira, bem como elaborar um diagnóstico dos diferentes usuários e das finalidades de uso das águas superficiais e subterrâneas. Devido a expressiva ocupação por projetos do Instituto Nacional de Colonização e Reforma Agrária (INCRA), também se mapeou o desmatamento na área objeto de estudo, até agosto de 2019, através do Programa de Desmatamento (PRODES) Digital do Instituto Nacional de Pesquisas Espaciais (INPE), para subsidiar algumas sugestões em relação aos impactos nas águas.

\section{MATERIAIS E MÉTODOS}

Para a confecção de tabelas, gráficos e mapas temáticos, foi utilizado o Banco de Dados de Outorgas de Direito de Uso dos Recursos Hídricos em Rondônia, do período de 2010 a 2019, disponibilizado pela SEDAM, através da Coordenadoria de Recursos Hídricos (COREH) (RONDÔNIA, 2020).

As planilhas em formato ODS (Open Office) foram convertidas para o formato XLS (Excel) e filtrados os campos que foram trabalhados: coordenadas geográficas, municípios, usuários e finalidades de uso das outorgas superficiais e subterrâneas.

No mapa de desmatamento da bacia foram utilizados dados do PRODES Digital/INPE (INPE, 2019), Imagens LandSat 8/OLI, órbita/ponto 231/067, 231/068, 232/067, 232/068 de 05/08/2019, com 30 metros de resolução espacial em formato vetorial (shapefile) esses dados possuem nível de precisão próximo a 95\%, 
sendo feito a junção e o recorte da área de interesse.

O Software QGis 3.4 (Madeira) foi usado na elaboração dos mapas da bacia com a utilização de dados vetoriais da SEDAM (RONDÔNIA, 2002c) em formato shp recortados a partir das sub-bacias hidrográficas de Rondônia, também utilizou-se como fonte, dados do Sistema de Proteção da Amazônia (SIPAM) (BRASIL, 2010), malha viária federal, do Departamento de Estradas de Rodagens, Infraestrutura e Serviços Públicos (DER/RO) (RONDÔNIA, 2017), malha viária estadual, da Fundação Nacional do Índio (FUNAI) (2019), as terras indígenas do Brasil, do Instituto Brasileiro de Geografia e Estatística (IBGE), malha municipal (IBGE, 2018) e a base cartográfica contínua do Brasil 1:1.000.000 - BCIM (IBGE, 2016), bem como os projetos de colonização do INCRA (INCRA, 2020), que aplicou-se o recorte com a respectiva ferramenta de geoprocessamento.

\section{Localização e Aspectos Gerais}

O Rio Jaru localiza-se na Amazônia Meridional Brasileira, sua área de drenagem de 7.261,5844km², foi subdividida em Alto Rio Jaru $\left(3.921,8658 \mathrm{~km}^{2}\right)$ e Baixo Rio Jaru $\left(3.339,7186 \mathrm{~km}^{2}\right)$, conforme trabalho técnico da SEDAM (RONDÔNIA, 2002c), pertence à margem esquerda da bacia do rio Machado - o maior rio totalmente rondoniense que deságua no rio Madeira e este por sua vez é um dos principais afluentes da margem direita do rio Amazonas (Figura 1).

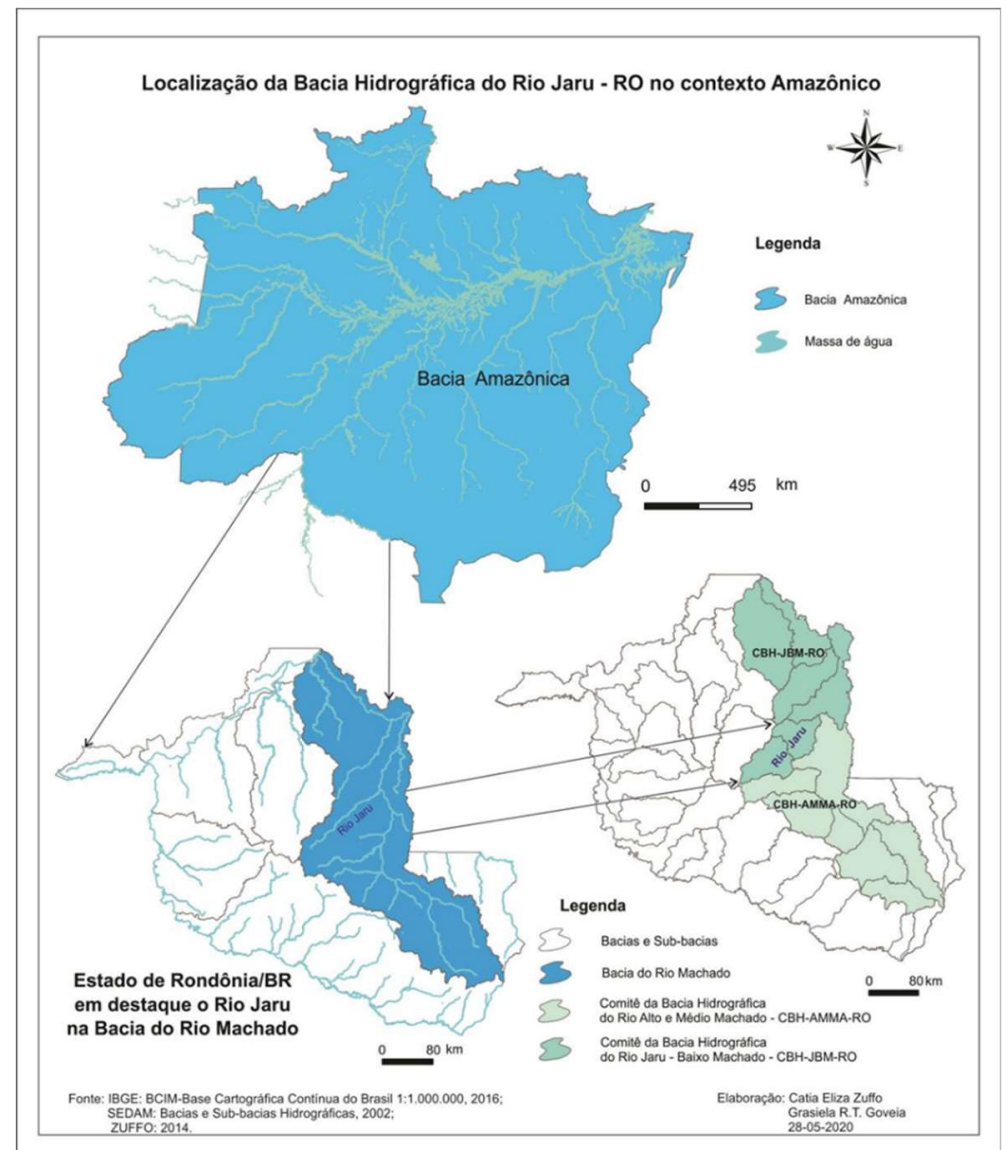

Figura 1: Localização da bacia hidrográfica do Rio Jaru - RO no contexto Amazônico. Fonte: Gonçalves et al. (2019a).

Nesta mesma figura 1, pode-se observar a subdivisão do rio Machado em dois Comitês de Bacias Hidrográficas, instituídos em 2014, porém ainda aguardando instalação, o do alto e médio curso, composto 
por sete sub-bacias é denominado Comitê da Bacia Hidrográfica do Rio Alto e Médio Machado (CBH-AMMARO) e o outro, composto por seis sub-bacias, denominado de Comitê da Bacia Hidrográfica do Rio Jaru - Baixo Machado (CBH-JBM-RO) (RONDÔNIA, 2014b; 2014c), portanto a bacia objeto deste estudo é uma referência a este Comitê.

As principais nascentes das cabeceiras do Rio Jaru são encontradas nos municípios de Governador Jorge Teixeira e Jaru, localizando-se na Terra Indígena Uru-Eu-Wau-Wau que perfaz ao todo $18.610,961 \mathrm{~km}^{2}$ (FUNAI, 2019), sendo o principal centro dispersor de águas do Estado, porém deste montante, apenas 603,150 km² $^{2}(3,24 \%)$ pertencem à bacia hidrográfica do Rio Jaru, sendo 453,924 km² (2,44\%) no município de Governador Jorge Teixeira, $146,585 \mathrm{~km}^{2}(0,79 \%)$ no município de Jaru e $2,641 \mathrm{~km}^{2}(0,015)$ no município de Mirante da Serra.

A bacia Hidrográfica do Rio Jaru drena área de nove municípios, a saber: Ariquemes, Cacaulândia Jaru, Theobroma, Nova União, Vale do Paraíso, Mirante da Serra, Governador Jorge Teixeira e Ouro Preto do Oeste, porém a figura 2 demonstra uma variabilidade expressiva no tamanho destas unidades territoriais segundo o IBGE (IBGE, 2018), bem como a área e percentual destes municípios em relação à bacia em estudo (Tabela 1), sendo destaque o município de Jaru cuja cidade homônima é o principal centro regional e onde está localizada a sede provisória para apoio ao processo de instalação deste Comitê.

Os dados divulgados pelo Censo Demográfico do IBGE (IBGE, 2011) demonstram que o município de Jaru se destaca tanto no seu entorno como em nível estadual, pois, dos 52 municípios rondonienses, ocupa do 60 ao 9o lugar no ranking em vários quesitos, tais como, no produto interno bruto - PIB; rebanho agropecuário, indústria e serviços.

Registra-se que Gonçalves et al. (2019a; 2019b) descreveram diversos aspectos físicos da área que corresponde ao CBH-JBM-RO, bem como discorreram sobre a importância da participação dos municípios na gestão das águas através dos comitês de bacia hidrográfica, abordando como estudo de caso este $\mathrm{CBH}$, em função das distâncias e outras especificidades da região amazônica.

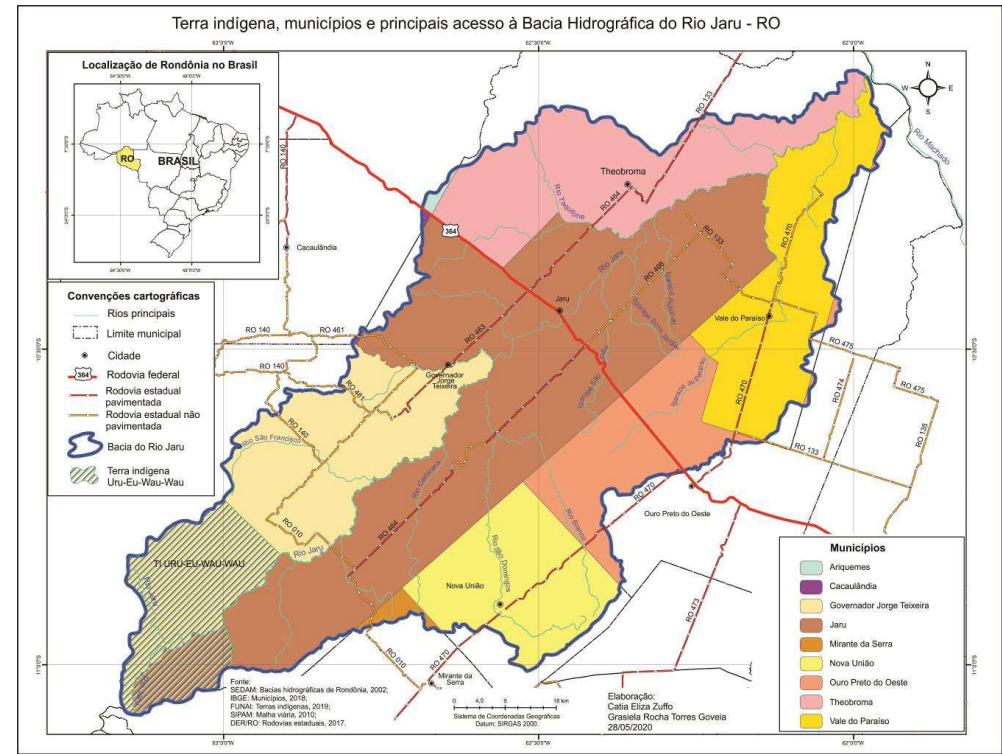

Figura 2: Terra indígena, municípios e principais vias de acesso à Bacia Hidrográfica do Rio Jaru - RO. Fonte: Gonçalves et al. (2019a). 
Tabela 1: Dados dos Municípios que compõem a bacia hidrográfica do Rio Jaru - RO.

\begin{tabular}{l|l|l|l}
\hline Municípios & $\begin{array}{l}\text { Área da unidade territorial } \\
\text { conforme IBGE (2018) }\end{array}$ & Área na bacia & \% na bacia \\
\hline Ariquemes & $4.426,571 \mathrm{~km}^{2}$ & 12,438 & 0,281 \\
\hline Cacaulândia & $1.961,778 \mathrm{~km}^{2}$ & 5,211 & 0,265 \\
\hline Governador Jorge Teixeira & $5.067,384 \mathrm{~km}^{2}$ & $1.320,504$ & 26,05 \\
\hline Jaru & $2.944,128 \mathrm{~km}^{2}$ & $2.833,767$ & 96,25 \\
\hline Mirante da Serra & $1.191,875 \mathrm{~km}^{2}$ & 39,888 & 03,35 \\
\hline Nova União & $807,126 \mathrm{~km}^{2}$ & 649,605 & 80,48 \\
\hline Ouro Preto do Oeste & $1.969,850 \mathrm{~km}^{2}$ & 604,322 & 30,68 \\
\hline Theobroma & $2.197,413 \mathrm{~km}^{2}$ & 988,299 & 44,97 \\
\hline Vale do Paraíso & $965,676 \mathrm{~km}^{2}$ & 817,009 & 84,60 \\
\hline
\end{tabular}

Fonte: Brasil (2018).

O principal acesso à área de estudo é a BR 364 (BRASIL, 2010), mas há várias rodovias estaduais que gradativamente estão sendo asfaltadas, a exemplo das RO 470, 464, 463 e 133 (RONDÔNIA, 2017), além de uma significativa malha de estradas vicinais.

Na bacia do Rio Jaru, localiza-se um expressivo polo da economia do estado, em que as atividades principais são do ramo agropecuário, o qual causa vários impactos ambientais, sendo os recursos hídricos de extrema importância para o processo de crescimento econômico da bacia.

\section{RESULTADOS E DISCUSSÃO}

Com base nas outorgas emitidas em áreas dos municípios que fazem parte da bacia hidrográfica do Rio Jaru/RO, conforme dados disponibilizados pela COREH/SEDAM (RONDÔNIA, 2020), a figura 3 representa a evolução quantitativa das outorgas emitidas tanto superficiais quanto subterrâneas, totalizando 152 no período em estudo. Enquanto o ano de 2010 não apresentou nenhuma informação, o ano de 2011 foi o que registrou o maior quantitativo de outorgas.

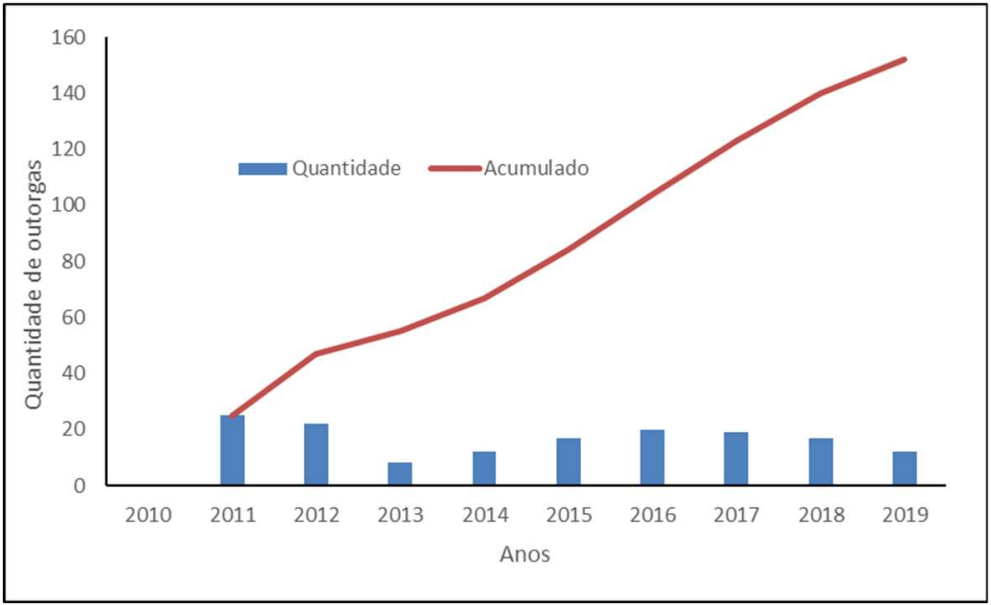

Figura 3: Evolução do número de outorgas emitidas na bacia do Rio Jaru - RO, entre 2010 a 2019. Fonte: Banco de Dados de Outorgas da SEDAM (RONDÔNIA, 2020).

Em relação às outorgas emitidas por tipo de captação na bacia em todo o período, 83,5\% (127 outorgas) das outorgas concedidas foram para águas superficiais, enquanto $16,5 \%$ (25 outorgas) para fontes subterrâneas. As outorgas de águas superficiais na bacia em estudo estão relacionadas à presença de grande quantidade de corpos de águas superficiais na região.

Isto também pode ser observado na maioria dos estados brasileiros, em que apenas 4 estados 
outorgam maior captação para água subterrânea, no restante dos estados as captações superficiais representam mais de $50 \%$ da vazão total outorgada (ANA, 2019).

As estimativas de finalidades de usos de recursos hídricos na bacia em estudo demonstraram que para as outorgas de água superficial, o setor de psicultura mostrou-se dominante, com $79 \%$ das outorgas, seguido pelas finalidades de uso doméstico $6 \%$ e industrial $5 \%$, os outros usos: de lançamentos de efluentes, irrigação de lavouras de café, e irrigação de pastagens/bovinocultura representaram juntos cerca de $10 \%$ do total de outorgas, como pode ser observado na tabela 2.

Esses resultados são condizentes com a realidade econômica da região e do estado de Rondônia em que a maior parte da vazão outorgada é para a aquicultura (ANA, 2019).

Tabela 2: Finalidade de usos das outorgas de Águas Superficiais emitidas para a bacia do Rio Jaru - RO, entre 2010 a 2019.

\begin{tabular}{l|l|l|l|l|l|l|l|l|l|l}
\hline Finalidades de uso de água superficial & $\mathbf{2 0 1 0}$ & $\mathbf{2 0 1 1}$ & $\mathbf{2 0 1 2}$ & $\mathbf{2 0 1 3}$ & $\mathbf{2 0 1 4}$ & $\mathbf{2 0 1 5}$ & $\mathbf{2 0 1 6}$ & $\mathbf{2 0 1 7}$ & $\mathbf{2 0 1 8}$ & $\mathbf{2 0 1 9}$ \\
\hline Piscicultura & - & 14 & 22 & 2 & 8 & 11 & 15 & 10 & 10 & 9 \\
\hline Industrial & - & 5 & - & - & - & - & 1 & - & - & 1 \\
\hline Uso Doméstico & - & - & - & 5 & 2 & - & - & 1 & - & - \\
\hline Irrigação/Pastagem/Bovinocultura & - & - & - & - & - & 2 & - & 1 & - & - \\
\hline Lançamento de Efluentes & - & - & - & - & - & - & 2 & - & 1 & 1 \\
\hline Irrigação/Lavoura/Café & - & - & - & - & - & - & - & 3 & 1 & - \\
\hline
\end{tabular}

Fonte: Banco de Dados de Outorgas da SEDAM (RONDÔNIA, 2020).

$\mathrm{Na}$ tabela 2, a psicultura apresenta o maior quantitativo em todos os anos, exceto em $2013 \mathrm{em}$ que o uso doméstico obteve mais outorgas.

A piscicultura brasileira está avançando, nos últimos anos, a partir de 2014, a produção de peixes de cultivo saltou 31\% no país: de 578.800 toneladas para 758.006 toneladas (BRASIL, 2020), sendo o estado de Rondônia destaque no cenário nacional como o maior produtor de espécies nativas do País, por possuir um conjunto de fatores naturais que justificam esse aumento da atividade, como as condições climáticas, a proximidade de um amplo mercado consumidor, topografia plana das propriedades, somado à alta disponibilidade de água que asseguram as sete bacias hidrográficas existentes, colocam o Estado em destaque na produção aquícola brasileira (MEANTE et al., 2017).

O estado de Rondônia, conta com, aproximadamente 16 mil hectares de espelho d'água. Ainda assim, em termos de produtividade, o estado teve decréscimo da sua produção. Um dos fatores levantados é devido à baixa organização da cadeia produtiva, aliada a falta de regulamentação ambiental definitiva e desburocratização do acesso às licitações. O estado esteve em segundo lugar no país no ranking da piscicultura em 2017, porém no ano de 2018 e 2019 foi superado pelo estado de São Paulo, passando a ocupar a terceira colocação do país. Rondônia enfrentou problemas ambientais, mercadológicos e sanitários o que levou a um recuou de 5,5\% em comparação a 2018 (BRASIL, 2020).

Na espacialização dos pontos outorgados de água superficial (figura 4), percebe-se certa distribuição das outorgas na área antropizada da referida bacia, com uma concentração um pouco mais expressiva na margem direita da sub-bacia Baixo Rio Jaru. 


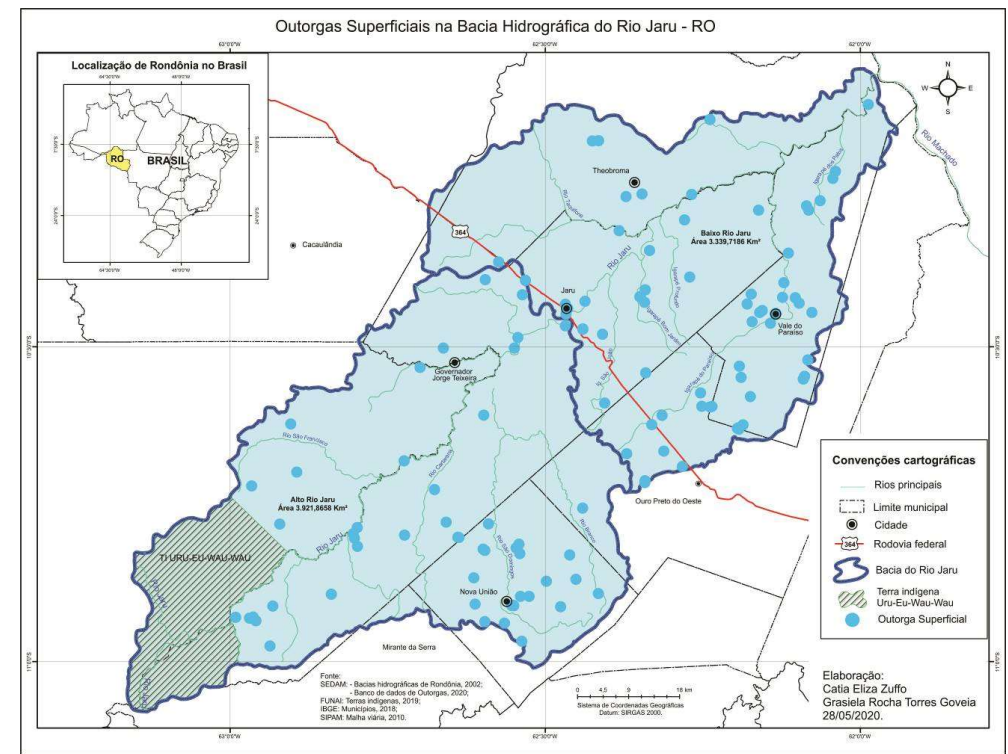

Figura 4: Distribuição das outorgas de águas superficiais de 2010 a 2019 na bacia hidrográfica do Rio Jaru - RO. Fonte: Gonçalves et al. (2019b).

A respeito das outorgas emitidas para a utilização das águas subterrâneas, a bacia possui poucos pontos cadastrados, sendo um cenário diferente das outorgas de águas superficiais, em que a finalidade de uso dominante foi o doméstico (48\%), seguido pelo uso industrial (44\%), já a piscicultura, irrigação/pastagem/bovinocultura tiveram pouca representatividade sendo $4 \%$ cada uma, como pode ser observado na tabela 3 o quantitativo de outorgas para os anos estudados.

Tabela 3: Finalidade de usos das outorgas de Águas Subterrâneas emitidas entre 2010 a 2019 para a bacia do Rio Jaru RO.

\begin{tabular}{l|l|l|l|l|l|l|l|l|l|l}
\hline $\begin{array}{l}\text { Finalidades de uso de } \\
\text { Águas Subterrâneas }\end{array}$ & $\mathbf{2 0 1 0}$ & $\mathbf{2 0 1 1}$ & $\mathbf{2 0 1 2}$ & $\mathbf{2 0 1 3}$ & $\mathbf{2 0 1 4}$ & $\mathbf{2 0 1 5}$ & $\mathbf{2 0 1 6}$ & $\mathbf{2 0 1 7}$ & $\mathbf{2 0 1 8}$ & $\mathbf{2 0 1 9}$ \\
\hline Piscicultura & - & - & - & - & - & - & 1 & - & - & - \\
\hline Industrial & - & - & - & 1 & 2 & 1 & 1 & - & 5 & 1 \\
\hline Uso Doméstico & - & 6 & - & - & - & 3 & - & 3 & - & - \\
\hline $\begin{array}{l}\text { Irrigação/Pastagem/ } \\
\text { Bovinocultura }\end{array}$ & - & - & - & - & - & - & - & 1 & - & - \\
\hline
\end{tabular}

Fonte: Banco de Dados de Outorgas da SEDAM (RONDÔNIA, 2020).

No que tange aos usos subterrâneos as outorgas ocorrem na maioria nas zonas urbanas ou perto delas (Figura 5), que é onde se concentram os usuários que utilizam a água para o consumo humano e uso industrial, normalmente é utilizada para substituir ou complementar consumo dos usuários, já que o abastecimento público em períodos de estiagem pode ficar comprometido e não atender toda a demanda necessária para diversos usos.

Ressalta-se que é dispensado a outorga para pequenos volumes quando residenciais, de acordo com a Lei Complementar no 255, Art. 27 (RONDÔNIA, 2002a) e a resolução no 04 do CRH/RO (RONDÔNIA, 2014c), pois são considerados usos insignificantes, e, nessa categoria, se enquadram a maior parte da população das zonas urbanas localizadas dentro da bacia hidrográfica do Rio Jaru/RO. Desta forma, a utilização de água subterrânea tende a ser muito maior do que a registrada no banco de dados da COREH/SEDAM (RONDÔNIA, 2020), além de muitos usuários não declararem, já que é um processo voluntário. 


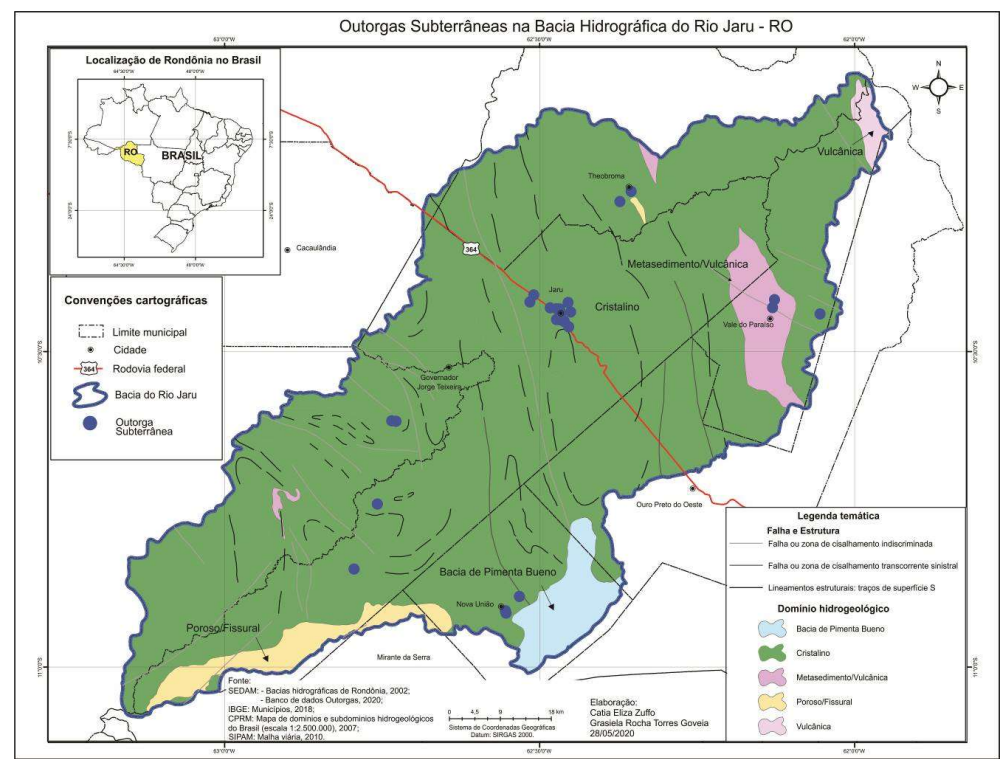

Figura 5: Distribuição das outorgas de águas subterrâneas de 2010 a 2019 na bacia hidrográfica do Rio Jaru - RO. Fonte: Gonçalves et al. (2019b).

Em relação aos domínios hidrogeológicos identificados principalmente pela litologia das rochas, objeto de mapeamento desenvolvido pelo Serviço Geológico do Brasil (CPRM) (BRASIL, 2007), cinco subdomínios encontram-se na bacia hidrográfica do Rio Jaru (Figura 5), sendo quatro em porções menores: Bacia de Pimenta Bueno, Metasedimento/Vulcânica, Poroso/Fissural e Vulcânica, enquanto que o mais expressivo foi o subdomínio hidrogeológico Cristalino. Apesar de todos apresentarem características limitantes a aquíferos potenciais, se comparados a outros domínios ou subdomínios, são mencionados como "uma alternativa de abastecimento de água às populações locais, sobretudo rurais, por meio de poços rasos $(<40 \mathrm{~m})$ " (ADAMY, 2010).

Atentando-se para a identificação dos municípios com maior número de outorgas dentro da bacia, na figura 6, destacam-se, em termos quantitativos de emissões, os municípios de Jaru e Vale do Paraíso pois são os que possuem maiores quantidades de outorgas. Uma das razões para esses quantitativos é por esses municípios possuírem maior área dentro da bacia, sendo que o município de Jaru apresenta um destaque tanto em área territorial, quanto em população.

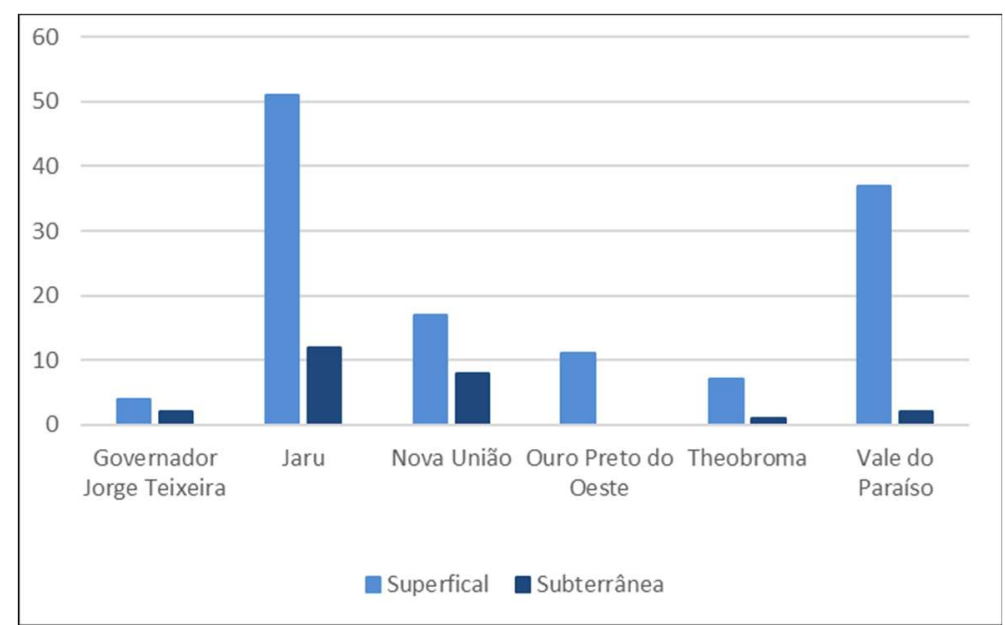

Figura 6: Distribuição das Outorgas por municípios, no período de 2010 a 2019, na bacia hidrográfica do Rio Jaru/RO. Fonte: Banco de Dados de Outorgas da SEDAM (RONDÔNIA, 2020). 
Segundo Rondônia (2018), o munícipio de Jaru, no ranking de maiores vazões retiradas, apresentou a quinta colocação no estado no ano de 2016 e o uso preponderante foi abastecimento animal.

Ao observar a figura 6, nota-se que três municípios que apresentam pequena porção territorial na bacia do Rio Jaru, não constam, pois não foram registradas outorgas para esse período do estudo e o município de Governador Jorge Teixeira foi o que apresentou menor quantitativo de outorgas, já o município de Ouro Preto do Oeste, cuja sede localiza-se em outra bacia hidrográfica, apresentou apenas outorgas para águas superficiais, sendo que grande parte delas foi para a piscicultura, uma vez que o governo estadual tem impulsionado o crescimento do mercado de peixes na região.

Em complementação à disposição da malha viária existente na bacia, bem como as fontes oficiais que mencionam a existência de um polo econômico na região, procurou-se identificar através do quadro 1 , os assentamentos realizados pelo INCRA na Bacia Hidrográfica do Rio Jaru/RO (INCRA, 2020), o que superou a expectativa inicial dos autores, visto que os 10 projetos de diversas modalidades ocupam 5.359,9981 km², a área da Terra Indígena Uru-Eu-Wau-Wau 603,150 km², restando a outras iniciativas de ocupação apenas $1.298,4363 \mathrm{~km}^{2}$ dos $7.261,5844 \mathrm{~km}^{2}$ que correspondem ao total da bacia hidrográfica objeto do estudo.

Quadro 1: Assentamentos realizados pelo INCRA na Bacia Hidrográfica do Rio Jaru/RO.

\begin{tabular}{|c|c|c|}
\hline Nome do Projeto & Município & Área em km² \\
\hline Projeto de Assentamento Palmares & Nova União & 46,1818 \\
\hline Projeto Integrado de Colonização Ouro Preto & Ouro Preto do Oeste & $1.718,8269$ \\
\hline Projeto de Assentamento do Jaru-Uaru & Jaru & 240,5505 \\
\hline Projeto de Assentamento Margarida Alves & Nova União & 78,2344 \\
\hline Projeto Integrado de Colonização Pe. Adolpho Rohl & Jaru & $3.209,0967$ \\
\hline Projeto de Assentamento Tarumã & Vale do Paraiso & 31,7738 \\
\hline Projeto de Assentamento 14 de Agosto & Ariquemes & 0,0098 \\
\hline Projeto de Assentamento Antonio Pereira Neri & Vale do Paraíso & 12,5550 \\
\hline Projeto de Assentamento Colina Verde & Governador Jorge Teixeira & 14,2371 \\
\hline Projeto de Assentamento Dirigido Burareiro & Ariquemes & 8,5318 \\
\hline \multicolumn{2}{|l|}{ Total da área dos Assentamentos na Bacia } & $5.359,9981$ \\
\hline
\end{tabular}

Fonte: INCRA (2020).

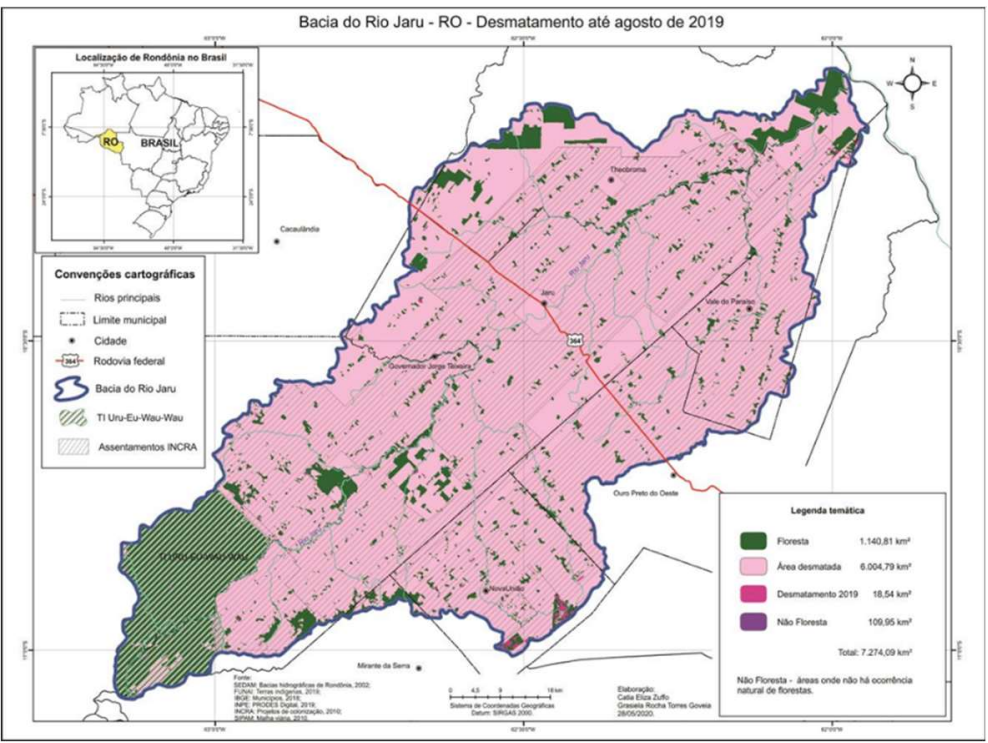

Figura 7: Desmatamento até agosto de 2019 na bacia hidrográfica do Rio Jaru - RO. Fonte: Gonçalves et al. (2019a).

A espacialização dos assentamentos realizados pelo INCRA e a área ocupada pela $\mathrm{TI}$, juntamente com o mapeamento do desmatamento na bacia (Figura 7), evidenciam o quanto as próprias políticas públicas de 
outrora, com a prática da máxima 'Integrar para não entregar' influenciaram no quadro atual e preocupante em que está bacia hidrográfica se encontra, com diversos impactos negativos com reflexos diretos e indiretos sobre a disponibilidade e qualidade da água.

Apesar de tão poucas áreas florestadas, mesmo no ano de 2019 houve o desmatamento até o mês de agosto de 18,54 km². Também preocupa as manchas expressivas de áreas desmatadas na vigência da Tl e cabeceiras desta bacia, o que merece atenção e atuação da FUNAl e parceiros.

\section{CONCLUSÕES}

A outorga é um dos instrumentos de grande importância para a efetiva gestão dos recursos hídricos, já que é a forma como o órgão gestor consegue controlar a demanda, avaliando a quantidade e qualidade da água, com o objetivo de garantir a interação entre os múltiplos usos da água, mitigando assim os conflitos dos usuários por esse bem indispensável para as suas atividades.

No diagnóstico das outorgas de direito de uso dos recursos hídricos, emitidas para a bacia hidrográfica do Rio Jaru, constatou-se que a grande maioria das outorgas foi para o uso em piscicultura, fato esperado pelo grande incentivo do governo para a produção do pescado, já que Rondônia ocupa o primeiro lugar no cenário nacional na produção de peixes em cativeiro.

Diante da extrema relevância desse bem para a bacia hidrográfica do Rio Jaru, é de suma importância dar atenção ao uso sustentável da água e à melhoria da qualidade de vida da população, desta forma, recomenda-se: a realização de vistorias frequentes na região da bacia para verificação do cumprimento por parte dos usuários dos termos das outorgas como a finalidade de uso da água, a vazão outorgada. É necessário o monitoramento da qualidade das águas nos cursos principais, especialmente em pontos a jusante dos lançamentos de efluentes.

Outro instrumento da Política Nacional de Recursos Hídricos que necessita ser implantado na bacia em estudo é a classificação dos corpos de água de acordo com as classes de usos preponderantes, o que gerará maior eficiência na análise dos pedidos de outorgas. Além disso, a bacia carece da implantação de um programa de conservação das matas ciliares e nascentes dos rios, com a recuperação de áreas degradadas, já que essa região passou por intenso desmatamento devido às atividades agropecuárias, sendo crescente a escassez de água na bacia durante o período de estiagem. É imprescindível a realização de programas de educação ambiental destinados à população, possibilitando debates relacionados à importância da conservação dos recursos hídricos.

Faz-se necessário priorizar e agilizar a instalação do Comitê da Bacia Hidrográfica do Rio Jaru - Baixo Machado/RO, juntamente com uma campanha para regularização dos usuários de águas que ainda não possuem cadastro no órgão gestor dos recursos hídricos em Rondônia, para que este colegiado, atualmente apenas legalmente instituído, tão logo seja implantado, possa atuar inclusive na mediação de conflitos entre usuários de água.

AGRADECIMENTOS: à Coordenação de Aperfeiçoamento de Pessoal Nível Superior - Brasil (CAPES) - Código 
de Financiamento 001. Ao Programa de Mestrado Profissional em Rede Nacional em Gestão e Regulação de Recursos Hídricos - PROFÁGUA, Projeto CAPES/ANA AUXPE №. 2717/2015. À Coordenadoria de Recursos Hídricos (COREH) da Secretaria de Estado do Desenvolvimento Ambiental (SEDAM).

\section{REFERÊNCIAS}

ADAMY, A.. Geodiversidade do estado de Rondônia. Porto Velho: CPRM, 2010.

ANA. Agência Nacional de Águas e Saneamento Básico. Outorga dos direitos de uso de recursos hídricos. Brasília: ANA, 2019.

BRASIL. Associação Brasileira de Piscicultura. Anuário Brasileiro da Piscicultura PEIXE BR. São Paulo: Peixe BR, 2020.

BRASIL. Lei n. 9.433, de 8 de janeiro de 1997. Institui a Política Nacional de Recursos Hídricos, cria o Sistema Nacional de Gerenciamento de Recursos Hídricos. Brasília: DOU, 1997.

BRASIL. Ministério da Defesa. Centro Gestor e Operacional do Sistema de Proteção da Amazônia. Centro Regional de Porto Velho: Malha viária Escala: 1:20.000. Porto Velho: Censipam, 2010.

BRASIL. Serviço Geológico do Brasil (CPRM). Mapa de domínios e subdomínios hidrogeológicos do Brasil. Sistema de Informações Geográficas (SIG), escala 1:2.500.000. Rio de Janeiro: CPRM, 2007

FUNAI. Fundação Nacional do Índio. Polígonos e Pontos das terras indígenas brasileiras. Brasília: FUNAI, 2019.

GONÇALVES, A. P. A.; ZUFFO, C. E.; GOVEIA, G. R. T.. Aspectos físicos da bacia hidrográfica do rio Jaru Baixo Machado Rondônia. In: PINHEIRO, L. S.; GORAYEB, A.. Geografia física e as mudanças globais. Fortaleza: UFC, 2019a.

GONÇALVES, A. P. A.; ZUFFO, C. E.; GOVEIA, G. R. T.. A importância da participação dos municípios na gestão das águas através dos comitês de bacias hidrográficas, o caso do CBH-JBM-RO. In: PINHEIRO, L. S.; GORAYEB, A.. Geografia física e as mudanças globais. Fortaleza: UFC, 2019b.

IBGE. Instituto Brasileiro de Geografia e Estatística. Base Cartográfica Contínua do Brasil 1:1.000.000: BCIM - versão 2016. Rio de Janeiro: DGC, 2016.

IBGE. Instituto Brasileiro de Geografia e Estatística. Censo Demográfico 2010: características da população e dos domicílios. Rio de Janeiro: IBGE, 2011.

IBGE. Instituto Brasileiro de Geografia e Estatística. Malhas territoriais: Malhas municipais 1:250.000. Rio de Janeiro: IBGE, 2018.

INCRA. Instituto Nacional de Colonização e Reforma Agrária. Projetos de Colonização: modalidades. Brasília: INCRA, 2020.
INPE. Instituto Nacional de Pesquisas Espaciais. Amazônia Legal: PRODES (desmatamento), dados do sistema de monitoramento do desmatamento da Amazônia Legal. São José dos Campos: INPE, 2019.

MEANTE, R. E. X.; DORIA, C. R. C.. Caracterização da cadeia produtiva da piscicultura no estado de Rondônia: desenvolvimento e fatores limitantes. Revista de Administração e Negócios da Amazônia, v.9, n.4, 2017. DOI: https://doi.org/10.18361/2176-8366/rara.v9n4p164-181

PORTO, M. F. A.; PORTO, R. L.. Gestão de Bacias Hidrográficas. Estudos Avançados, v.22, n. 63, p.33-60, 2008 .

RONDÔNIA. Resolução CRH/RO n. 04, de 18 de março de 2014. Dispõe sobre critérios para definição de derivações, captações, lançamentos de efluentes, acumulações e outras interferências em corpos de água de domínio do Estado de Rondônia que independem de outorga, que não estão sujeitos à outorga. Porto Velho: DOE, 2014a.

RONDÔNIA. Decreto 19.058, de 31 de julho de 2014. Institui o Comitê de Bacia Hidrográfica do Rio Alto e Médio Machado - CBH-AMMA-RO e dá outras providências. Porto Velho: DOE, 2014b.

RONDÔNIA. Decreto 19.059, de 31 de julho de 2014. Institui o Comitê de Bacia Hidrográfica do Rio Jaru - Baixo Machado CBH-JBM-RO e dá outras providências. Porto Velho: DOE, 2014c.

RONDÔNIA. Lei complementar 255 de 25 de janeiro de 2002. Dispõe sobre a Política Estadual de Recursos Hídricos do Estado de Rondônia e dá outras providências. Porto Velho: DOE, 2002a.

RONDÔNIA. Decreto n. 10.114 de 20 de setembro de 2002. Regulamenta a Lei Complementar no 255, de 25 de janeiro de 2002, que "Institui a Política, cria o Sistema de Gerenciamento e o Fundo de Recursos Hídricos do Estado de Rondônia, e dá outras providências". Porto Velho: DOE, 2002b.

RONDÔNIA. Departamento de Estradas de Rodagens, Infraestrutura e Serviços Públicos (DER/RO). Malha viária estadual atualização agosto 2017. Porto Velho, 2017.

RONDÔNIA. Secretaria de Estado do Desenvolvimento Ambiental. Atlas Geoambiental de Rondônia. Porto Velho: SEDAM, 2002.

RONDÔNIA. Secretaria de Estado do Desenvolvimento Ambiental. Coordenadoria de Recursos Hídricos. Banco de dados de outorgas de direito de uso dos recursos hídricos em Rondônia de 2010 a 2019. Porto Velho: COREH, 2020. 
RONDÔNIA. Secretaria de Estado do Desenvolvimento

Ambiental. Plano Estadual de Recursos Hídricos do Estado

de Rondônia: Relatório Final. Curitiba, 2018.

A CBPC - Companhia Brasileira de Produção Científica (CNPJ: 11.221.422/0001-03) detém os direitos materiais desta publicação. Os direitos referem-se à publicação do trabalho em qualquer parte do mundo, incluindo os direitos às renovações, expansões e disseminações da contribuição, bem como outros direitos subsidiários. Todos os trabalhos publicados eletronicamente poderão posteriormente ser publicados em coletâneas impressas sob coordenação da Sustenere Publishing, da Companhia Brasileira de Produção Científica e seus parceiros autorizados. Os (as) autores (as) preservam os direitos autorais, mas não têm permissão para a publicação da contribuição em outro meio, impresso ou digital, em português ou em tradução. 